\title{
Update on Special IMS 50th Anniversary Symposium at MS\&T 2017
}

\author{
Ryan M. Deacon ${ }^{1}$
}

Published online: 15 May 2017

(C) Springer Science+Business Media New York and ASM International 2017

Recently, I shared the news that the International Metallographic Society would be celebrating its 50th anniversary this year, in part by having a special symposium at the MS\&T conference in Pittsburgh, Pa., in October. This symposium will feature the previous recipients of the various honors that IMS bestows upon its members, including the Henry Clifton Sorby Award, the JacquetLucas Award, and the Buehler Best Paper Award.

Abstract submissions for MS\&T symposia closed just a few days ago, and I am happy to report that interest in the IMS symposium was quite high. We have received a number of abstracts from previous award recipients, in addition to some contributed talks from non-awardees. When the invitation to present a talk was sent to previous award winners, they were encouraged to select of topic of their own interest, be it an update on the work for which they were originally recognized by IMS, or something new entirely. Looking through the abstracts we have received, I see the speakers took this to heart; the topic areas for the proposed talks are quite diverse and will be of interest to a wide audience.

The symposium coordinators are currently in the process of organizing the talks into sessions. In the next issue of $M M A$, I look forward to sharing some of the topics that our

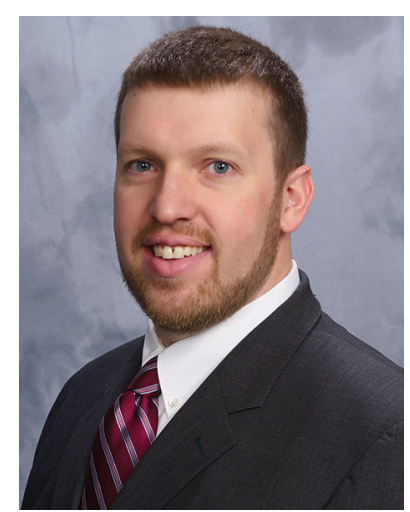

speakers will present. Additionally, $M M A$ is planning to publish a special issue of manuscripts from this symposium; more details to follow. In the meantime, I hope that our readers will keep this special symposium in mind as you make plans for MS\&T-it will be an excellent opportunity to see presentations from the luminaries in our field! I look forward to seeing you in Pittsburgh in October.

Ryan M. Deacon

ryan.deacon@asminternational.org

1 United Technologies Research Center, 411 Silver Lane, East Hartford, CT 06108, USA 